\title{
Analysis of Students' Errors on the Fraction Calculation Operations Problem
}

\author{
Wirda Safriani ${ }^{1}$, Said Munzir ${ }^{2}$, M. Duskri ${ }^{3}$, Ikhsan Maulidi ${ }^{4}$ \\ ${ }^{1}$ Departement of Mathematics Education, Syiah Kuala University, \\ ${ }^{3}$ Departement of Mathematics Education, UIN Arraniry University, \\ ${ }^{2,4}$ Departement of Mathematics, Syiah Kuala University, \\ ${ }^{4}$ Correspondence Address; ikhsanmaulidi@unsyiah.ac.id
}

\begin{abstract}
Students' errors on fraction problems often occur, especially in fraction counting operations. This error shows that the ability of students who do not understand the fraction problems. To overcome these errors, attention from the teacher is needed so that mistakes can be resolved. The purpose of this study is to describe students' errors in the fraction counting operation problem on each indicator, which is related to converting mixed fractions to ordinary fractions, determining fractions of value, and performing fraction addition and subtraction operations. This research is a qualitative descriptive study. The results showed that the majority of students experienced concept errors on each indicator requested in this study. Also, students make other mistakes such as mistakes of principle and carelessness.
\end{abstract}

Keywords: Error analysis, arithmetic operations, and fractions.

\section{INTRODUCTION}

Understanding the ability to calculate operations on students is one of the activities that should be done by the teacher in the learning process. This aims to reduce the occurrence of concept errors in students which can become obstacles to other concepts being taught. Zakiah et al (2013) stated that errors that occur should have been realized by the teacher during the learning process so that alternative actions can be taken immediately.

One of the problems that often involve students' mistakes in mathematics is the fraction counting problem. The concept of fractional counting operations is one of the important concepts to be well understood by students because the material will be studied on an ongoing basis at the next level. Also, fractions cover basic concepts and are one of the prerequisite problems for studying and understanding other mathematical problems (Nuraini et al, 2016).

Error checking in students can be done by conducting tests. According to Usodo (in Badaruddin et al, 2016) that by knowing the mistakes in solving a problem in mathematics, it can be traced to the students' learning difficulties in learning mathematics. Broadly speaking, errors that might occur in solving mathematical problems include: The first, concept error is an error when understanding the concepts being taught. Second, the principle error is a mistake when connecting several concepts or facts in solving a problem. Third, carelessness which includes errors in counting or writing errors in solving problems (Nurianti et al, 2015).

The results of the research by Indah Suciati and Dewi Sri Wahyuni (2018) in solving the problem of calculating fraction operations obtained information that: first, concept error, students do the addition and subtraction on the numerator and denominator of the fraction, did not do the denominator equations beforehand or do the equation of the denominator but the wrong way; second, namely principle errors, students solve problems not in accordance with the order of the problems, and consistently use the wrong way of solving problems; third is carelessness, students are wrong in determining the results of operations. 
Prevention of errors such as the above needs to be done because it will be fatal to other material errors. The causes of elementary school students' mistakes in solving problems are mostly due to the lack of conceptual understanding (Herholdt \& Sapire, 2014). Besides, mistakes arise as a result of student learning difficulties. Students focus too much on memorizing algorithms or formulas in solving mathematical problems (Badaruddin et al, 2016). Overall dominant Students' errors take the form of concept errors and are caused byways of learning that are not continuous, and the lack of mastery of prerequisite material (Zakiah, 2013).

A teacher needs to master and understand well the patterns of errors that occur in students in learning mathematics. Therefore, it is important for teachers to be able to improve their competencies, so that they can solve problems that occur. Teacher competence in implementing teaching and learning processes related to teaching knowledge (pedagogical knowledge) and content (content knowledge). The combination of the two knowledge is known as pedagogical content knowledge (PCK). Good PCK teachers are identified with professional teachers. Being a professional teacher is not by birth, but is formed through a long process and a very long time so that it can produce the skills and knowledge needed in their fields (Nur, 2014).

Teacher's Pedagogical Content Knowledge (PCK) can be generated from the teaching experience of the teacher in the classroom. The longer the teaching experience in the classroom, the PCK the teacher will get better. This will be useful for teachers to overcome students' mistakes in solving problems, one of which is on the material for calculating fractions. Research on students' mistakes in fraction problem generally has been widely carried out by previous researchers (Yulianingsih 2018; Ramlah, Bennu, and Paloloang 2017; Ulfah and Fitriyani, 2017; Nugroho, 2017; Setyowati, Trapsilasiwi, and Fatahillah, 2017; Saputro, 2016; Nuraini, Suhartono, and Yuniawantika, 2016). However, what about the mistakes of students taught by experienced teachers. This study discusses the mistakes of Banda Aceh Elementary School students in fractional counting operation material.

Based on this explanation, this research explores any mistakes made by students in public elementary schools in Banda Aceh on the problem of fractional operations?

\section{THE RESEARCH METHODS}

This study aims to describe the errors of the fifth-grade students of SDN in Banda Aceh on the problem for calculating fractions with a qualitative descriptive approach. The sample in this study amounted to 61 grade V students spread over two SDN in Banda Aceh, namely SDN 57 and SDN 44. The selection of the school was based on the length of experience of the teacher teaching at the school. The deadline for the experience of selected teachers is more than 10 years and the teacher has received certification. This research was conducted on August 1 - 20 2019. To analyze the students' mistakes in solving problems, an essay test was used. The test consists of 6 items about fraction counting operations, with the following indicators: First, converting mixed fractions to ordinary fractions is found in item number 1; Second, determine the fractions worth in item 2; Third, determine the results of addition and subtraction of fractions contained in item 3 and 4; Fourth, solving the problem of fractions in real life is contained in item 5 . 
The data in this study are the results of student tests and interview results. The first test, in the form of an essay test, was conducted on all study samples. While interviews were conducted with 3 representatives of high, medium and low ability students who were able to communicate well in each school. The ability to sort is based on information from the class teacher concerned. Then, the six students are given a second test that aims to see the consistency of student answers. Then the test is analyzed for errors that occur in students' answers to describe the error.

\section{THE RESULTS OF THE RESEARCH AND THE DISCUSSION}

After conducting tests on both SDN 57 and SDN 44 students tabulated, the following information was obtained:

a. Analysis of the ability to convert mixed fractions into ordinary fractions.

Student test results on the ability to convert mixed fractions into ordinary fractions are shown in the following table

Table 1. Percentage of Students' Errors in Item Number On

\begin{tabular}{lcccc}
\hline Kind of mistakes & $\begin{array}{c}\text { Total students in } \\
\text { SDN 57 }\end{array}$ & $\begin{array}{c}\text { Total students } \\
\text { in SDN 44 }\end{array}$ & Total & Percentage \\
\hline concept errors & 10 & 26 & 36 & $59,01 \%$ \\
principle errors & 3 & 2 & 5 & $8,19 \%$ \\
carelessness & - & 1 & 1 & $1,63 \%$ \\
No answer & 9 & 2 & 11 & $18,03 \%$ \\
correctly & 6 & 3 & 9 & $14,75 \%$ \\
\hline
\end{tabular}

The ability of students to convert mixed fractions into ordinary fractions (indicator 1 ) in the above table shows that more students make mistakes in concept than students who make principle mistakes in the process of solving. As for examples of student answers that are wrong concepts can be seen in the following picture.

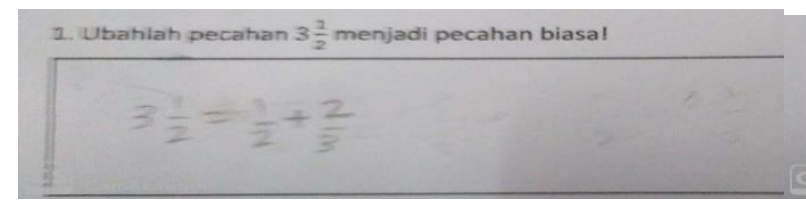

Figure 1a: an answer to the $1^{\text {st }}$ test

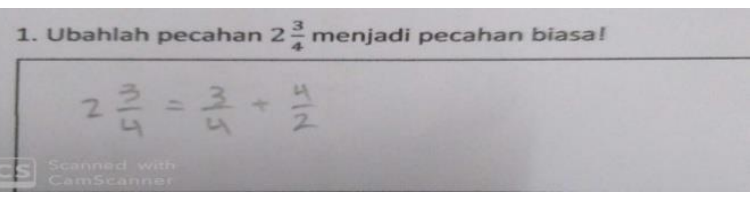

Figure 1b: an answer to the $2^{\text {nd }}$ test

Based on the results of interviews with high-ability students, answers to the first test students obtained information: that the way to change mixed fractions into ordinary fractions is to separate these numbers into ordinary fractions. Like $3 \frac{1}{2}$ to be $\frac{1}{2}+\frac{2}{3}$. Fraction $\frac{1}{2}$ is obtained from existing fractions, while $\frac{2}{3}$ is obtained from the denominator which is represented by an integer. This is reinforced by the consistency of students in answering on the 2 nd test.

Based on the results of interviews with capable students, it was found that the two students made a mistake in principle. Examples of answers to capable students can be seen in the following picture.

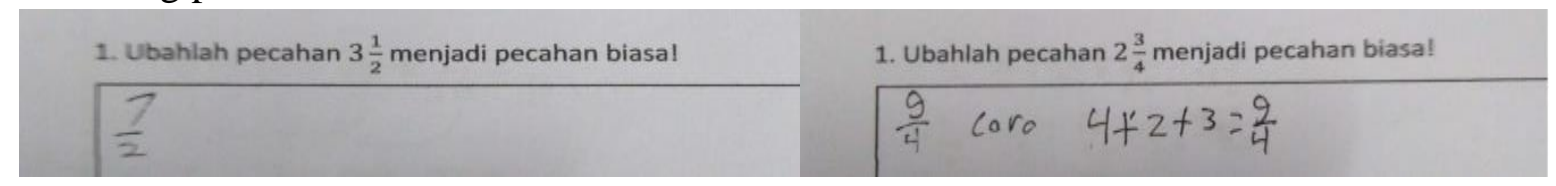


In Figure $2 \mathrm{a}$ it appears that the students' answers are correct. However, after being interviewed it turned out that students made a mistake in principle. Based on the results of the interviews with the two students, the same information was obtained, namely that they stated that the solution was by adding integers to the numerator and denominator and then by the denominator itself. The number 7 in the numerator shown in Figure 2a, students count using 2 $+3+1=7$, which is a misconception and carelessness. This is reinforced by the consistency of students' answers in answering to the 2nd test (figure $2 b$ ).

Based on the results of interviews with low-ability students it was found that the two students did not understand the concept. So, students do not answer the questions both on the first test and the second test (figure $2 b$ ).

b. Analysis of the ability to determine the equality of rational number

The second indicator requested in the test of this study is that students can determine the equivalent number of a ratio number. Student test results on the second indicator can be seen in Table 2 below:

Table 2. Percentage of Students' Errors in Item Number Two

\begin{tabular}{lcccc}
\hline Kind of mistakes & $\begin{array}{c}\text { Total students in } \\
\text { SDN 57 }\end{array}$ & $\begin{array}{c}\text { Total students } \\
\text { in SDN 44 }\end{array}$ & Total & Percentage \\
\hline concept errors & 18 & 30 & 48 & $78,68 \%$ \\
principle errors & - & - & - & - \\
carelessness & - & 1 & 1 & $1,63 \%$ \\
No answer & 8 & 2 & 10 & $16,39 \%$ \\
Correctly & 2 & 0 & 2 & $3,27 \%$ \\
\hline
\end{tabular}

In table 2., information is obtained that more students make mistakes in concept than students who make carelessness in the completion process. Based on the results of interviews with students of high ability, it was found that only one student answered correctly, while one other person answered incorrectly. Examples of incorrect student answers are shown in the following figure.

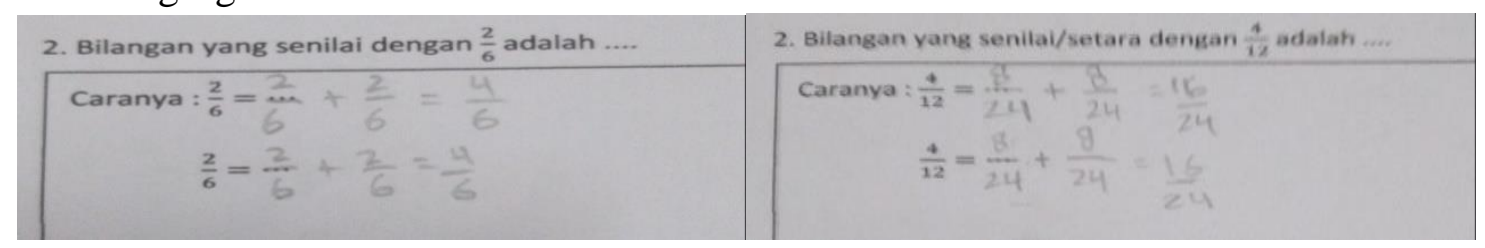

Figure 3a: an answer to the 1st test

Figure 3b: an answer to the 2nd test

Based on the results of interviews about the answers to the first test, information was obtained that the solution was to use the concept of addition. Also, when asked about the meaning of equality fractions, students do not know. This is reinforced by the consistency of students in answering on the 2 nd test.

The results of interviews with capable students are being obtained that only one student answers correctly, and one other person answers incorrectly. Examples of student answers that answer incorrectly can be seen in the following picture. 


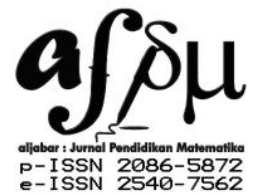

Al-Jabar: Jurnal Pendidikan Matematika

Vol. 10, No. 2, 2019, Hal 307 - 318

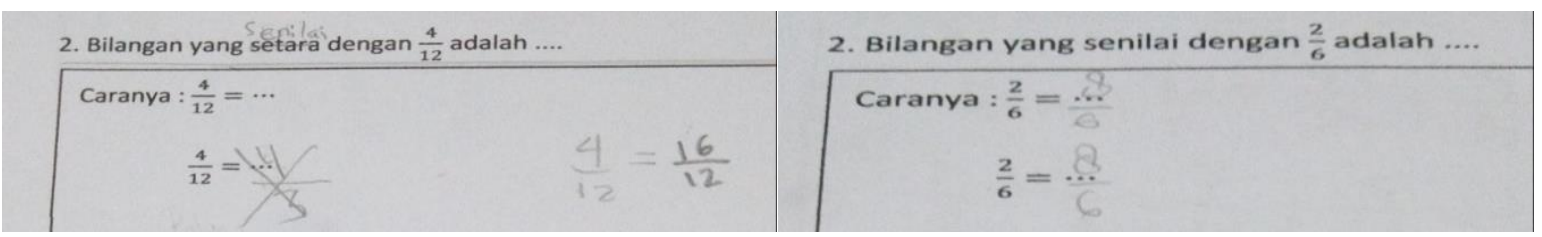

Figure 4a: an answer to the 1st test

Figure 4b: an answer to the 2nd test

Based on the results of the interviews obtained information that students add up the numerator and denominator to be a numerator in new fractions that are valued at $\frac{4}{12}$. This is reinforced by the consistency of students in answering on the 2nd test.

Based on the results of interviews with low-ability students obtained that the two students did not understand the concept. So, students do not answer the questions both on the first test and the second test.

c) Analysis of the ability to complete fractional count operations

The third indicator is completing fraction counting operations, such as addition, subtraction, multiplication, and division. However, what will be discussed in this study is only the addition and subtraction operations only. From some of the questions given, the researchers only discussed the questions that were made a lot of mistakes by students. These questions are numbered $3 \mathrm{c}$ and $4 \mathrm{c}$. Test results number $3 \mathrm{c}$ about fraction addition operations can be seen in the following table 3

Table 3. Percentage of Students' Errors in Item Number 3c

\begin{tabular}{lcccc}
\hline Kind of mistakes & $\begin{array}{c}\text { Total students in } \\
\text { SDN 57 }\end{array}$ & $\begin{array}{c}\text { Total students in } \\
\text { SDN 44 }\end{array}$ & Total & Percentage \\
\hline concept errors & 23 & 19 & 42 & $68,85 \%$ \\
principle errors & - & 3 & 3 & $4,91 \%$ \\
carelessness & 1 & 4 & 5 & $8,19 \%$ \\
No answer & 1 & 5 & 6 & $9,83 \%$ \\
correctly & - & - & - & - \\
Not simplify & 3 & 2 & 5 & $8,19 \%$ \\
\hline
\end{tabular}

Table 3 shows that more students make mistakes in concept than students who make carelessness in the completion process. Examples of high-ability student test results can be seen in the following figure.

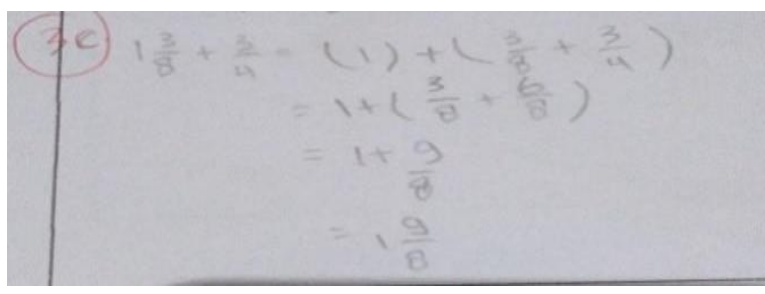

Figure 5a: an answer to the 1st test

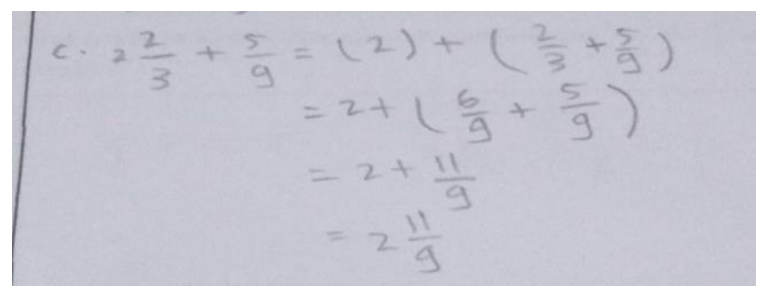

Figure 5b: an answer to the 2nd test

Based on the results of interviews with highly capable students, it was found that students did not make a concept mistake, only students made mistakes not to simplify fractions. For example (figure 5a) students only stop on answers $1 \frac{9}{8}$. This $1 \frac{9}{8}$ should be able to be simplified to $2 \frac{1}{8}$. Student answers (Figure $5 \mathrm{a}$ ) are reinforced by the consistency of student answers on the 
2nd test (Figure 5b). Then the answers of other high-ability students are as follows:

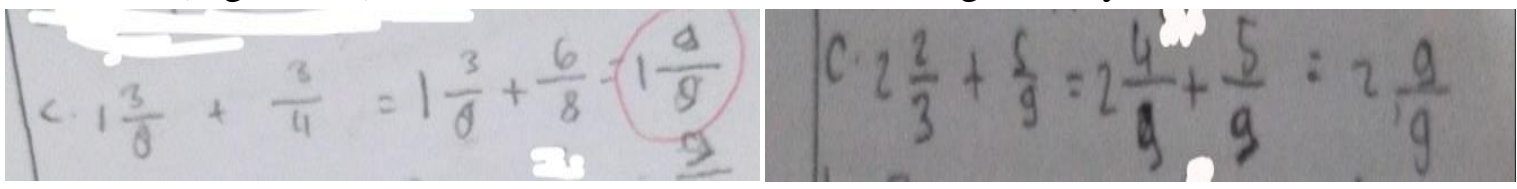

Figure 6a: an answer to the 1st test

Figure 6b: an answer to the 2nd test

The same mistakes as mistakes made by high-ability students at SDN 57 also occurred at SDN 44 (Figures 5a and 6a). Also, high-ability students at SDN 44 make carelessness when operating numbers. Thus, students' answers on the 2nd test were wrong (figure 6b). Examples of answers to capable students can be seen in the following picture

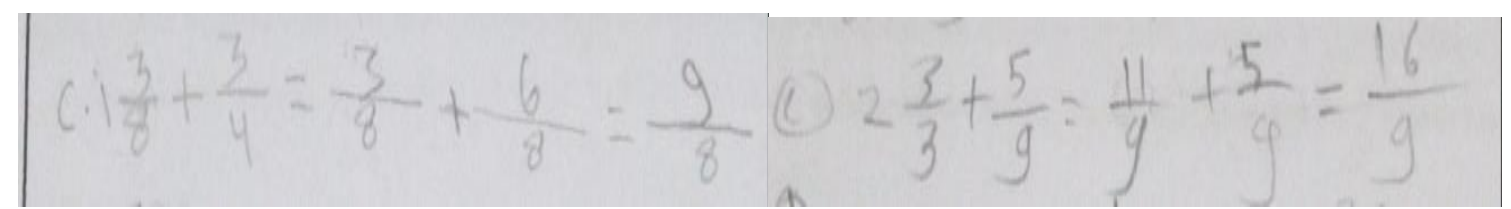

Figure 7a: an answer to the 1st test

Figure 7b: an answer to the 2nd test

Based on the results of interviews with medium-skilled students, it was found that students made a mistake in principle. On the 1st test, students are wrong because of the sum to the integers on the mixed fraction. Students state that the denominator for the denominator, then multiplied by the numerator, then sums them by integers. Like (8: 8) $x 3+1=3$. These results are used as a numerator. This error was confirmed in the 2 nd test. Next, the answers of other moderately capable students.

C. $1 \frac{7}{8}+\frac{3}{4}=1+\frac{3}{8}+\frac{3}{4}=1 \frac{6}{12}-\left(1 \frac{3}{8}+\frac{3}{4}=14 \frac{5}{52}+\frac{24}{32}=1 \frac{13}{32} \quad\right.$ <. $2 \frac{2}{3}+\frac{5}{9}=2+\frac{18}{27}+\frac{15}{27}=2 \frac{33}{27}$

Figure 8a: an answer to the 1st test

Figure 8b: an answer to the 2nd test

Based on the results of interviews with these students, it was found that students only made a carelessness on the 1st test, namely students summing the numerator by the numerator, and the denominator by the denominator. At the time of the interview, students are aware of these mistakes and try to correct them. The answer to the improvement can be seen in the section circled in the red pen (figure 8a). Carelessness on the 1st test is reinforced by the correct answers of students on the 2nd test. However, there are other errors in both the 1st and 2nd tests, where students do not simplify the fraction results obtained. The answers of students with low ability can be seen in the following figure.

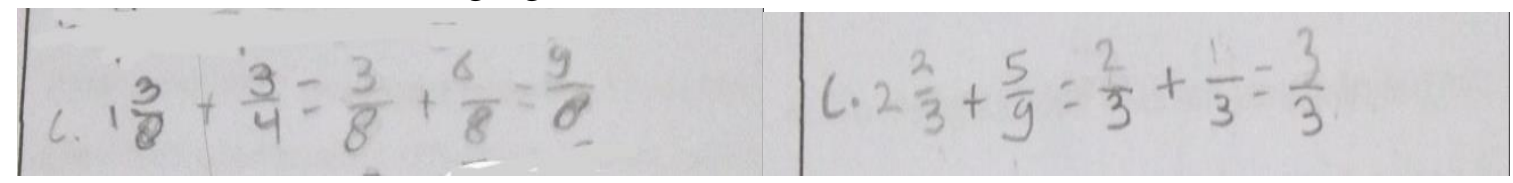

Figure 9a: an answer to the 1st test

Figure 9b: an answer to the 2nd test

Based on the results of interviews with students it was found that students were wrong in equating the denominator. Students state that the number in the denominator of the first fraction becomes the denominator in solving a problem. This error is included in the concept of equating denominator errors. This error is reinforced from the results of the 2 nd student test. Then, the answers of another low capable student are: 


\section{(3. $1 \frac{3}{8}+\frac{3}{4}=1 \frac{6}{12}$}

Figure 10a: an answer to the 1st test
Figure 10b: an answer to the 2nd test

Based on the results of interviews with students, it was found that students made a concept error in solving the problem. Students state that the solution is by directly summing the numerator by the numerator and the denominator by the denominator, without making the denominator equalized first. Student test results on the reduction problems of the ordinary fraction with different denominators. The percentage of test results can be seen in the following table 4:

Table 4. Percentage of Students' Errors in Item Number 4c

\begin{tabular}{lcccc}
\hline Kind of mistakes & $\begin{array}{c}\text { Total students in } \\
\text { SDN 57 }\end{array}$ & $\begin{array}{c}\text { Total students in } \\
\text { SDN 44 }\end{array}$ & Total & Percentage \\
\hline concept errors & 15 & 21 & 36 & $59,01 \%$ \\
principle errors & 1 & 4 & 5 & $8,19 \%$ \\
carelessness & 1 & 3 & 4 & $6,55 \%$ \\
No answer & 8 & 2 & 10 & $16,39 \%$ \\
correctly & 3 & 2 & 5 & $8,19 \%$ \\
Not simplify & - & - & - & - \\
\hline
\end{tabular}

In the table obtained information that fewer students can answer questions correctly than students who make mistakes. The examples of errors in high-ability students' answers can be seen in the following figure.

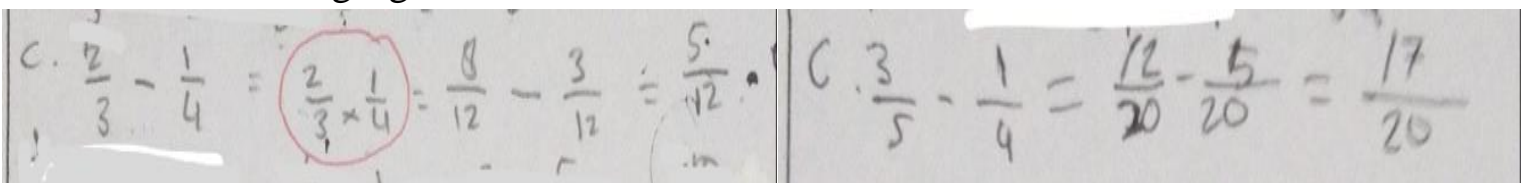

Figure 11a: an answer to the 1st test

Figure 11b: an answer to the 2nd test

Based on the results of the interview it was found that students only made a carelessness on the 1 st test. Such carelessness lies when wanting to equalize the denominator. Carelessness is only writing that is not needed and can be fatal because it changes the meaning of the problem. However, after the interview and was told his mistake, the students did not repeat the mistake on the 2nd test. This carelessness can be seen in the circled section using a red pen.

Medium-capable students only one student can answer correctly, while one more student makes a conceptual mistake when completing a fraction reduction operation. The answers of students who made a concept error can be seen in the following picture.

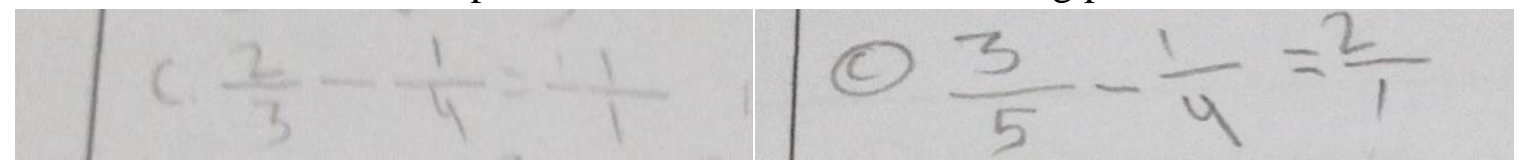

Figure 12a: an answer to the 1st test

Figure 12b: an answer to the 2nd test

Based on the results of interviews with students, it was found that students made a conceptual mistake in solving the problem of reducing fractions. Students state that the solution is by subtracting the numerator by the numerator and the denominator by the denominator 
without equalizing the denominator first. The error was reinforced from students' answers on the second test.

Then, low-ability students do not answer the questions given. Based on the results of the interview about the reasons for not answering, they said they did not know and could not. The student's disability because students do not understand the concept of reducing fractions.

c. Analysis of the ability to complete fraction counting operations in real life

Indicator 4 in this study is students can solve fractions problems related to real life. Student test results can be seen in the following table 5

Table 5. Percentage of Students' Errors in Item Number 5

\begin{tabular}{lcccc}
\hline Kind of mistakes & $\begin{array}{c}\text { Total students } \\
\text { in SDN 57 }\end{array}$ & $\begin{array}{c}\text { Total students } \\
\text { in SDN 44 }\end{array}$ & Total & Percentage \\
\hline concept errors & 11 & 24 & 35 & $57,37 \%$ \\
principle errors & 6 & 4 & 10 & $16,39 \%$ \\
carelessness & 1 & 2 & 3 & $4,91 \%$ \\
No answer & 10 & 3 & 13 & $21,31 \%$ \\
correctly & - & - & - & - \\
Not simplify & - & - & - & - \\
\hline
\end{tabular}

Based on the table, it was found that there were no students who could answer the questions correctly. Students who make mistakes in concept more than students who make mistakes in principle in solving problems. Examples of high-ability student answers can be seen in the following picture.

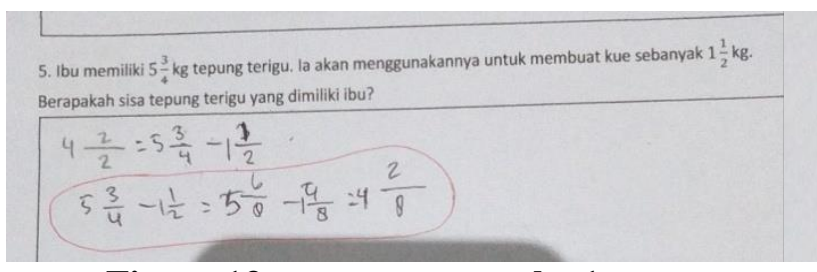

Figure 13a: an answer to the 1st test

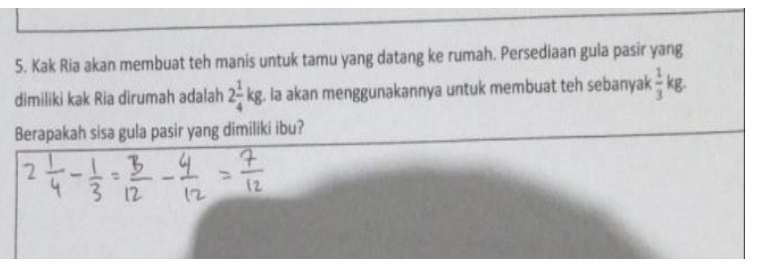

Figure 13b: an answer to the 2nd test

Based on the results of interviews with students it was found that students only made carelessness on the 1st test. Carelessness occurs because students do not write questions in the form of mathematics. After the researcher asks students to write down questions in mathematical form, students are aware and correct the wrong answers. The answer to improvement can be seen in the section circled in the red pen. Furthermore, students' mistakes on the 2 nd test are because the students only mastered one method of completion, namely the method used on the 1 st test. The answers of students who are medium-capable can be seen in the following picture.

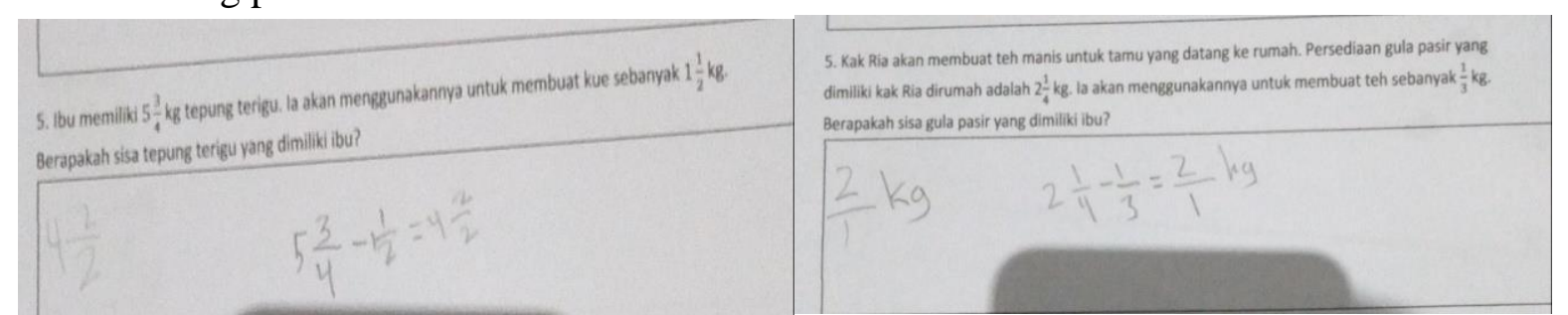

Figure 14a: an answer to the 1st test
Figure 14b: an answer to the 2nd test 
Based on the results of interviews with students, it was found that students made a conceptual mistake. This error is because students do not understand the concept. This mistake is the same as the mistake made by high-ability students. However, this student is confident in the answers he made. This concept error in students was reinforced by the answer to the 2nd test. Next, the example of other medium capable students' answers are:

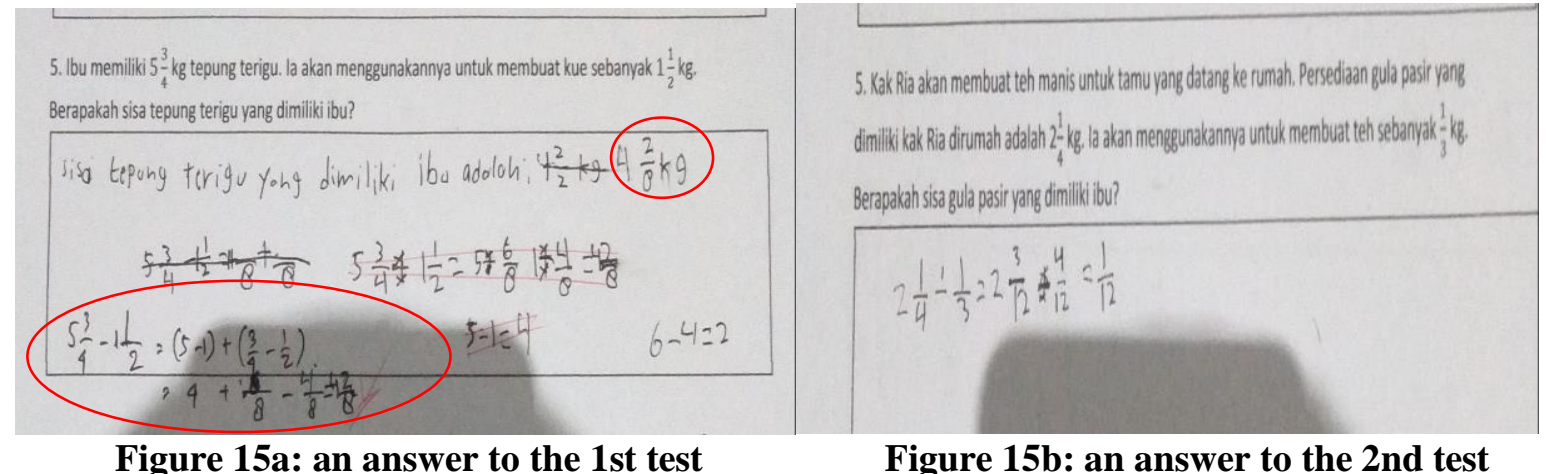

Based on the results of interviews with students, it was found that students only made the same carelessness with students with high mathematical abilities at the school. Likewise, with the second test, he made a mistake because he only mastered one way of completion. While students with low ability do not answer questions, because they cannot solve them.

Based on the findings obtained by the researcher, students make a lot of concept errors on each indicator. These kinds of student mistakes are students cannot convert mixed fractions into ordinary fractions and vice, students cannot simplify a fraction and cannot determine the fraction worth of a fraction, students are also wrong in equating the denominator to solve addition problems on fractions. When completing the subtraction problem students make a mistake by directly subtracting the numerator by the numerator and the denominator by the denominator. Also, mistakes made by students are caused by students only mastering one way of resolution, this is in line with previous studies (Fatahillah, 2017; Ramlah, Bennu, and Paloloang 2017; Rahma Santika and Prahmana 2018; Widiyanti and Yani, 2015; Sugiarti and Retnawati 2019; Perbowo and Anjarwati 2017; Bernard, Dwi Minarti and Hutajulu 2018; Nugroho, 2017; Tanjung and Nababan 2016; Nurkaeti 2018; Zhang, Stecker, and Beqiri 2017; Tong and Loc 2017; Westenskow and Moyer 2017 -Packenham 2016).

Based on the above studies in accordance with the results of research conducted by Indah Suciati and Dewi Sri Wahyuni, namely most students make a conceptual mistake. These errors are like students adding or subtracting numerators and numerators and denominators, miscalculating the denominator, incorrectly using operations, and being careless in counting. Besides, Badaruddin et al also stated that the Students' error factor was due to students not mastering the prerequisite concepts (such as the concept of simplifying fractions, and the concept of converting mixed fractions into ordinary fractions and vice versa), not yet understanding the concepts of addition and subtraction on fraction operations, and lacking able to arrange systematic steps in answering questions.

One of the obligations for teachers is to overcome the mistakes that occur in students so as not to repeat itself. Many ways can be taken in overcoming these mistakes, such as ways 


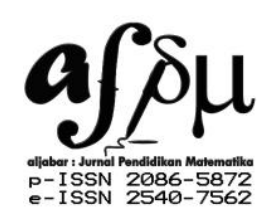

Al-Jabar: Jurnal Pendidikan Matematika

Vol. 10, No. 2, 2019, Hal 307 - 318

(techniques) of good teaching, so students can capture the knowledge given. Besides, a good mastery of the material is also very important for every teacher. As an experienced teacher, those two things must have been well mastered. So, it can be said that the teacher's Pedagogical Content Knowledge (PCK) is good. It is this good teacher PCK that provides a solution in overcoming students' mistakes. However, based on the results of the study, students taught by experienced teachers still make mistakes. The majority of students' mistakes lie in concept errors. That way, the length of experience of the teacher alone does not guarantee that the teacher's PCK is good and mistakes in students do not occur again. Need another effort that can help PCK teachers become good. One of them is an effort to assist teachers

\section{CONCLUSION AND SUGGESTION}

Based on the analysis of Students' errors above, it can be concluded that most students make concept mistakes. A small number of students make mistakes in principle and carelessness. Students' misconceptions when changing mixed fractions into ordinary fractions, making fractions settle without equating the denominator first, and students also make the mistake of adding or subtracting between the denominator infractions. This finding was confirmed by the research of Indah Suciati and Dewi Sri Wahyuni, as well as research by Badaruddin et al. Therefore, to overcome these mistakes an effort from the government and teachers is needed that can prevent mistakes from happening and can make students more easily remember the concept. One effort that can be done is by assisting the teacher's Pedagogical Content Knowledge (PCK)

\section{REFERENCES}

Aksoy, Can Parrot. (2017). Students' errors Fractions and Possible Causes of These Errors. Journal of Education and Training Studies, 5 (11), 219-233.

Badaruddin, et al. 2016. Analysis of Error in Solving Fraction Count Operations Problems on Class VII Students of SMP Negeri 10 Kendari. JPPM, 4 (2), 43-56.

Bernard, Martin, Eva Dwi Minarti, and Masta Hutajulu. 2018. "Constructing Student's Mathematical Understanding Skills and Self Confidence: Math Games with Visual Basic Applications for Microsoft Excel in Learning Phytagore at Junior High School." International Journal of Engineering \& Technology 7 (3.2): 732.

Ringing, Yasemin. (2019). Misconceptions of Primary Schools Students about The Subject of Fractions. International Journal of Evaluation and Research in Education, 8 (1), 29-38.

Fatahillah, Arif. 2017 "Analysis of Students' errors in Solving Mathematical Story Problems Based on Newman's Stages and Scaffolding Forms Given," 12.

Herholdt, Roelien \& Sapire, Ingrid. 2014. An Error Analysis in the Early Grades MathematicsA Learning Opportunity? South African Journal of Childhood Education - 4 (1): 42 - 60.

Nugroho, Reza Aji. 2017 "Analysis of Student Difficulties in Solving Story Problems on Fractional Materials in Terms of Polya Problem Solving," Kadikma, Vol. 8, No. 1, pp. 4051,15 . 


\section{$\underset{a}{a} \rho \mu$}

Al-Jabar: Jurnal Pendidikan Matematika

Vol. 10, No. 2, 2019, Hal 307 - 318

Nurianti, Evi et al. Analysis of Students' errors in solving mathematical problems in fractions of Algebraic Material in Class VIII of Middle School. Untan. Pontianak.

Nuraini, Ni Luh Sakinah, Suhartono Suhartono, and Yuniawantika Yuniawantika. 2016. "Student Mistakes in Fraction Addition and Reduction Operations in Class VI Elementary Schools." Primary Schools: Theory Studies and Educational Practices 25 (2): 168-75.

Nur, Lutfia. 2014. Pedagogical Content Knowledge (PCK) experienced teachers and prospective teachers. Thesis. Indonesian education university.

Nurkaeti, Nunuy. 2018. "Polya's Strategy: An Analysis Of Mathematical Problem Solving Difficulty In 5th Grade Elementary School. "Edu Humanities | Journal of Basic Education Cibiru Campus 10 (2): 140.

Perbowo, Krisna Satrio, and Restu Anjarwati. 2017. "Analysis Of Students' Learning Obstacles On Learning Inverse Function Material." Infinity Journal 6 (2): 169.

Rahmasantika, Danty, and Rully Charitas Indra Prahmana. 2018. "Analysis of Student Mistakes in Fraction Count Operations Based on Student Intelligence Levels." Journal of Honai Math 1 (2): 81.

Ramlah, Ramlah, Sudarman Bennu, and Baharuddin Paloloang. 2017. "Analysis of Students' errors in Solving Problem of Addition and Subtraction of Fractions in Class Vii SMPN Madani Integrated Model. "JIPMat 1 (2).

Salleh, Zakiah et al. Analysis of Types of Error in Addition and Rejection Fraction Operations. Journal of Mathematical Education 1 (1).

Saputro, Bagus Ardi. 2016. "Mathematical Reasoning Ability of Students Learning to Operate on Fractions Using Traditional Games," 10.

Setyowati, Henny, Dinawati Trapsilasiwi, and Arif Fatahillah. 2017 "Identification of Student Misconceptions in Solving Problem Questions on Fraction Number Material Using the Certainty of Response Index (Cri)," 10.

Suciati, Indah, and Dewi Sri Wahyuni. 2018. "Analysis of Students' errors in Solving Mathematical Problems in Fraction Count Operations in Class V Students of Pengawu Elementary School." Journal of Mathematics Research and Learning, 11 (2).

Sugiarti, L., \& Retnawati, H. (2019, October). Analysis of student difficulties on algebra problem solving in junior high school. In Journal of Physics: Conference Series (Vol. 1320, No. 1, p. 012103). IOP Publishing.

Tanjung, Henra Saputra, and Siti Aminah Nababan. 2016. "The Influence of the Use of Play Learning Methods Against Student Math Learning Outcomes of Fractional Material in Class Iii Elementary School 200407 Hutapadang" 3 (1): 8.

Tong, Duong Huu, and Nguyen Phu Loc. 2017. "Students' Errors In Solving Mathematical Word Problems And Their Ability In Identifying Errors In Wrong Solutions". European Journal of Education Studies. 3 (6): 16. 


\section{a $\int \rho \mu$}

Al-Jabar: Jurnal Pendidikan Matematika

Vol. 10, No. 2, 2019, Hal 307 - 318

Ulfah, Siti, and Harina Fitriyani. 2017 "Certainty Of Response Index (CRI): Misconception of Junior High School Students on Fractional Materials," 9.

Uzel, Devrim. (2018). Investigation of Misconceptions and Errors About Division Operations in Fractions. Journal of Educational Research, 6 (11), 2656-2662.

Westenskow, Arla, and Patricia Seray Moyer-Packenham. 2016. "Using an Iceberg Intervention Model to Understand Equivalent Fraction Learning When Students with Mathematical Learning Difficulties Use Different Manipulatives. International Journal for Technology in Mathematics Education, 23(2), 45.

Widiyanti, Putri and Ahmad Yani. 2017. "Analysis of Student Difficulties in Solving Problem Material in the Form of Algebra in Grades in Junior High School," 17.

Yulianingsih, Alifah. 2018. "Analysis of the Error of the Concept of Fractions in Class VIII A Junior High School Students 13 One Roof Tanjung Pinang." Journal of Mathematics Education 7: 8 .

Zhang, Dake, Pamela Stecker, and KlestiBeqiri. 2017. "Strategies Students With and Without Mathematics Disabilities Use When Estimating Fractions on Number Lines." Learning Disability Quarterly. 40 (4): 225-36 